\title{
Surface pretreated low-temperature aluminum-aluminum wafer bonding
}

\author{
Andreas P. Hinterreiter ${ }^{1} \cdot$ Bernhard Rebhan $^{2} \cdot$ Christoph Flötgen $^{2} \cdot$ \\ Viorel Dragoi ${ }^{2} \cdot$ Kurt Hingerl $^{1}$
}

Received: 10 June 2016/Accepted: 5 August 2017/Published online: 18 August 2017

(c) The Author(s) 2017. This article is an open access publication

\begin{abstract}
Aluminum-aluminum wafer bonding is becoming increasingly important in the production of CMOS microelectromechanical systems. So far, successful bonding has required extreme processing temperatures of $450{ }^{\circ} \mathrm{C}$ or more, because the chemically highly stable oxide layer acts as a diffusion barrier between the two aluminum metallization layers. By using the ComBond ${ }^{\circledR}$ system, in which a surface treatment and subsequent wafer bonding are both performed in a high vacuum cluster, for the first time successful $\mathrm{Al}-\mathrm{Al}$ wafer bonding was possible at a temperature of $150{ }^{\circ} \mathrm{C}$. The bonded interfaces were characterized using C-mode scanning acoustic microscopy and transmission electron microscopy, and featured areas of oxide-free, atomic contact.
\end{abstract}

\section{Introduction}

Thermo-compression wafer bonding is a key technology for the wafer-level production of hermetically sealed cavities, which are essential for the functioning of many microelectromechanical systems (MEMS). Compared to other established materials, aluminum has a number of benefits: low price, high thermal and electrical conductivities and relatively high electromigration resistivity (if small concentrations of copper are added (Lloyd 1999)). These properties, combined with its complementary metal

Andreas P. Hinterreiter

andreas.hinterreiter@jku.at

1 Center of Surface and Nanoanalytics, Johannes Kepler University, Linz, Austria

2 EV Group, Schärding, Austria oxide semiconductor (CMOS) compatibility, make aluminum a promising candidate for the fabrication of CMOSMEMS, in which the actuator part is bonded to the electrical circuit.

However, the chemically highly stable oxide layer acts as a diffusion barrier between the two aluminum metallization layers. Successful Al-Al wafer bonding has thus required extreme processing temperatures so far. Table 1 lists experimental parameters extracted from a number of reports on $\mathrm{Al}-\mathrm{Al}$ wafer bonding. In established processes, a high pressure-usually several tens of MPa (Yun et al. 2008a; Malik et al. 2014, 2015)—is used to break the oxide in order to establish diffusion channels for $\mathrm{Al}$ atoms. As a calculation shows (Rebhan and Hingerl 2015), the elastic energy is much too low to influence the bonding between atoms directly but the applied stress and the resulting strain breaks up the surface layer. The wafers are bonded at high temperatures, usually in the range of $400-550{ }^{\circ} \mathrm{C}$ (Yun et al. 2008a; Cakmak et al. 2009; Froemel et al. 2011; Malik et al. 2014, 2015). In recent experiments, Malik et al. were able to reduce the required bonding temperature to about $350{ }^{\circ} \mathrm{C}$ by depositing the $\mathrm{Al}$ metallization layer onto an intermediate $\mathrm{SiO}_{2}$ layer (Malik et al. 2015). Notably, Akatsu et al. used an ultra-high surface activated bonding set-up (Akatsu et al. 1997) to bond cubes of single crystalline aluminum at room temperature (with a bonding pressure of $40 \mathrm{MPa}$ ) (Akatsu et al. 1999). This technique was also used on wafer-level for copper (Kim et al. 2003), but there is no account for surface activated $\mathrm{Al}-\mathrm{Al}$ waferlevel bonding.

In the present experiments, for the first time successful $\mathrm{Al}-\mathrm{Al}$ wafer bonding was performed at temperatures as low as $150{ }^{\circ} \mathrm{C}$ using the ComBond ${ }^{\circledR}$ surface preparation process. 
Table 1 Comparison of experimental parameters from different reports on successful Al-Al wafer bonding

\begin{tabular}{|c|c|c|c|c|c|c|}
\hline & Al thickness & $\mathrm{Cu}$ content & Bond area & Force & Pressure & Temperature \\
\hline Yun et al. (2008a) & $2 \mu \mathrm{m}$ & $0-4 \%$ & $600-1200 \mathrm{~mm}^{2 \mathrm{a}}$ & $60 \mathrm{kN}^{\mathrm{a}}$ & $50-100 \mathrm{MPa}$ & $450{ }^{\circ} \mathrm{C}$ \\
\hline Yun et al. (2008b) & $2 \mu \mathrm{m}$ & $2 \%$ & n. a. & $9-18 \mathrm{kN}$ & n. a. & $450{ }^{\circ} \mathrm{C}$ \\
\hline Cakmak et al. (2009) & $500 \mathrm{~nm}$ & $0 \%$ & $175 \mathrm{~cm}^{2}$ & $60 \mathrm{kN}$ & $3.4 \mathrm{MPa}$ & $400-550{ }^{\circ} \mathrm{C}$ \\
\hline Froemel et al. (2011) & $1 \mu \mathrm{m}$ & n. a. & n. a. & n. a. & $4.5 \mathrm{MPa}$ & $450{ }^{\circ} \mathrm{C}$ \\
\hline Malik et al. (2014) & $1 \mu \mathrm{m}$ & $0 \%$ & $525 \mathrm{~mm}^{2}$ & $18-36 \mathrm{kN}$ & 34-69 MPa & $400-550{ }^{\circ} \mathrm{C}$ \\
\hline Malik et al. (2015) & $1 \mu \mathrm{m}$ & $0 \%$ & $525 \mathrm{~mm}^{2}$ & $36-60 \mathrm{kN}$ & 69-114 MPa & $300-550{ }^{\circ} \mathrm{C}$ \\
\hline
\end{tabular}

n. a. = not available

${ }^{\text {a }}$ Values estimated from description of frame structure

\section{Experimental}

The substrates used for the present bonding experiments were $200 \mathrm{~mm}$ diameter silicon wafers with a $20 \mathrm{~nm} \mathrm{Ti}$ adhesion/barrier layer on top. metallization layers of $99.5 \%$ $\mathrm{Al}$ and $0.5 \% \mathrm{Cu}$ with a thickness of $300 \mathrm{~nm}$ were deposited on top of the Ti film using two different techniques: standard sputter deposition and aluminum low pressure seed (ALPS). ALPS differs from the standard deposition mainly in terms of processing pressure and temperature. While the standard deposition was performed at $215^{\circ} \mathrm{C}$ with an $\mathrm{Ar}$ pressure of $3.3 \times 10^{-3} \mathrm{mbar}$, the ALPS process was carried out at only $30{ }^{\circ} \mathrm{C}$ with an Ar pressure of $5.33 \times 10^{-5}$ mbar. The surface roughness of the wafers was determined from $2 \mu \mathrm{m} \times 2 \mu \mathrm{m}$ atomic force microscopy (AFM) scans recorded in tapping mode.

Conventional wafer bonds were produced in a standard thermo-compression wafer bonding system $\left(\mathrm{EVG}^{\circledR}\right.$ 520IS). For the low-temperature bonds, the $\mathrm{EVG}^{\circledR} 580 \mathrm{ComBond}^{\circledR}$, a fully automated, high-vacuum dry surface pretreated wafer bonding system was used. In the ComBond ${ }^{\circledR}$ system, a robot arm transfers the wafers from a central chamber to several modules. This way, a surface preparation step can be performed before the bonding without exposing the wafers to air. The surface treatment is a proprietary EV Group process with special plasma, gas and pressure parameters. It acts as a "mild" oxide removal process, revealing oxide-free surfaces while only negligibly enhancing the sample's surface roughness. Prior to the bonding experiments, $\mathrm{Al}_{2} \mathrm{O}_{3}$ removal rates of up to $15 \mathrm{~nm} \mathrm{~min}{ }^{-1}$ were confirmed by thickness measurements of atomic layer deposited $\mathrm{Al}_{2} \mathrm{O}_{3}$ films on $\mathrm{Si}$ substrates. The bonding chamber in the ComBond ${ }^{\circledR}$ is practically identical to that of the $\mathrm{EVG}^{\circledR}$ 520IS. In both set-ups, a bonding force of $60 \mathrm{kN}$ was used. Since all bonded wafer pairs presented in this paper are full area bonds of unstructured wafers (bonding area: $314 \mathrm{~cm}^{2}$ ), this force corresponds to a bonding pressure of 1.9 MPa. The interfaces of the bonded wafer pairs were characterized by C-mode scanning acoustic microscopy (C-SAM), scanning electron microscopy (SEM) and transmission electron microscopy (TEM).

\section{Results and discussion}

\subsection{Wafers}

Figure 1 shows AFM images of the surfaces of the two different kinds of wafers. The standard deposited $\mathrm{Al}$ developed grains with lateral sizes of $300 \mathrm{~nm}$ to $700 \mathrm{~nm}$, while the grains of the ALPS wafers are significantly smaller with $200 \mathrm{~nm}$ to $300 \mathrm{~nm}$. The root mean square (RMS) surface roughness was found to be about $1.2 \mathrm{~nm}$ for both kinds of wafers. TEM measurements revealed that the grains extend throughout the whole layer for both deposition types. Furthermore, the thickness of the native aluminum oxide is about $3 \mathrm{~nm}$ to $4 \mathrm{~nm}$, which is in agreement with typical reported values (Hart 1956; Evertsson et al. 2015).

\subsection{Conventional Al-Al wafer bonding}

The present attempts to bond two unstructured $200 \mathrm{~mm}$ diameter $\mathrm{Al}$ wafers on a conventional set-up were unsuccessful. Figure 2 shows a typical C-SAM result of a wafer pair (standard $\mathrm{Al}$ deposition) bonded at $550{ }^{\circ} \mathrm{C}$. The image shows many weakly bonded areas. The sound velocity in $\mathrm{Al}$ is very close to the sound velocity in aluminum oxide, and factors of 10 to 20 different to the one of voids (air). This is why C-SAM allows to detect defects with layer-tolayer distances even in the sub-micrometer range. The bond quality was found to be extremely sensitive to local pressure variations. The low bonding pressure of only $1.9 \mathrm{MPa}$ (which is the maximum possible with this specific bonding 


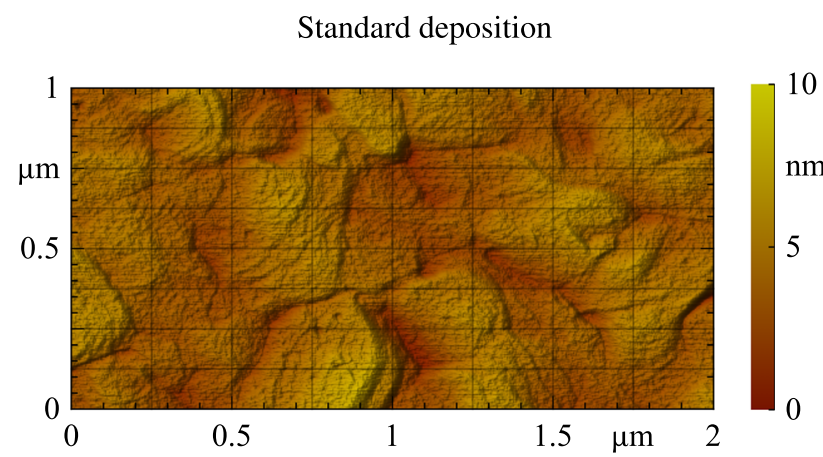

ALPS

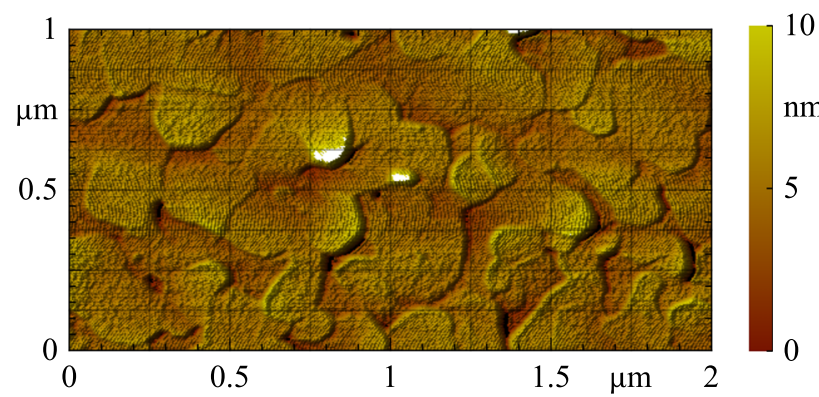

Fig. 1 AFM images of the Al wafer surfaces. The different processing conditions result in larger grains for the standard deposition and smaller grains for the ALPS wafers

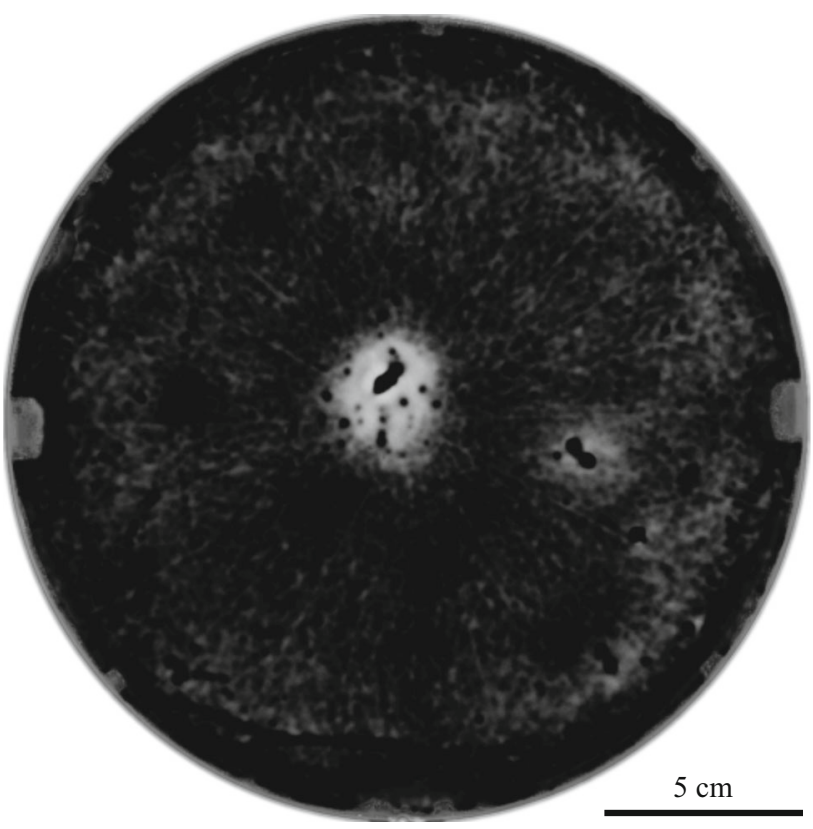

Fig. 2 Typical C-SAM result of $200 \mathrm{~mm}$ diameter $\mathrm{Al}$ wafers (standard deposition) bonded conventionally at $550{ }^{\circ} \mathrm{C}$

set-up) was not enough to reproduce the results of Cakmak et al. (2009), who were able to bond unstructured $150 \mathrm{~mm}$ wafers with a pressure of $3.4 \mathrm{MPa}$. A cross-sectional SEM inspection showed that the high bonding temperature had caused the Ti barrier layer to dissociate into individual, droplet-like grains. Furthermore, between the two aluminum layers the undamaged $\mathrm{Al}$ oxide was visible, which was also detectable by Auger electron spectroscopy depth profiling. The oxide layer obstructs diffusion of $\mathrm{Al}$ atoms between the two metallization layers, making grain growth across the original interface impossible. The results with ALPS wafers were similar.

\subsection{Low-temperature surface pretreated Al-Al Wafer Bonding}

Figure 3 shows a typical C-SAM result of a ComBond ${ }^{\circledR}$ surface pretreated, low-temperature $\left(150{ }^{\circ} \mathrm{C}\right)$ bonded wafer pair. Due to the surface pretreatment, which removes the native $\mathrm{Al}$ oxide prior to the bonding process, the wafers can be bonded at temperatures lower than any values reported in literature (see Table 1). The C-SAM image shows only minor interface defects. The larger ones, with a lateral extent of a few millimeters, were mainly caused by particles. While the origin of the smaller defects is still open for discussion, it could be shown that they can be partially cured by an additional thermal annealing step. Figure 4 (top) shows sectors of C-SAM measurements recorded (1) directly after wafer bonding in the ComBond ${ }^{\circledR}$ at $150{ }^{\circ} \mathrm{C}$ for $1.5 \mathrm{~h}$, and after subsequent annealing for $1 \mathrm{~h}$ at (2) $250{ }^{\circ} \mathrm{C}$, and at (3) $350{ }^{\circ} \mathrm{C}$. To detect areas of weak bonding, the images were binarized at a certain threshold value, leaving only those pixels colored that were originally part of unbonded areas. For better visibility

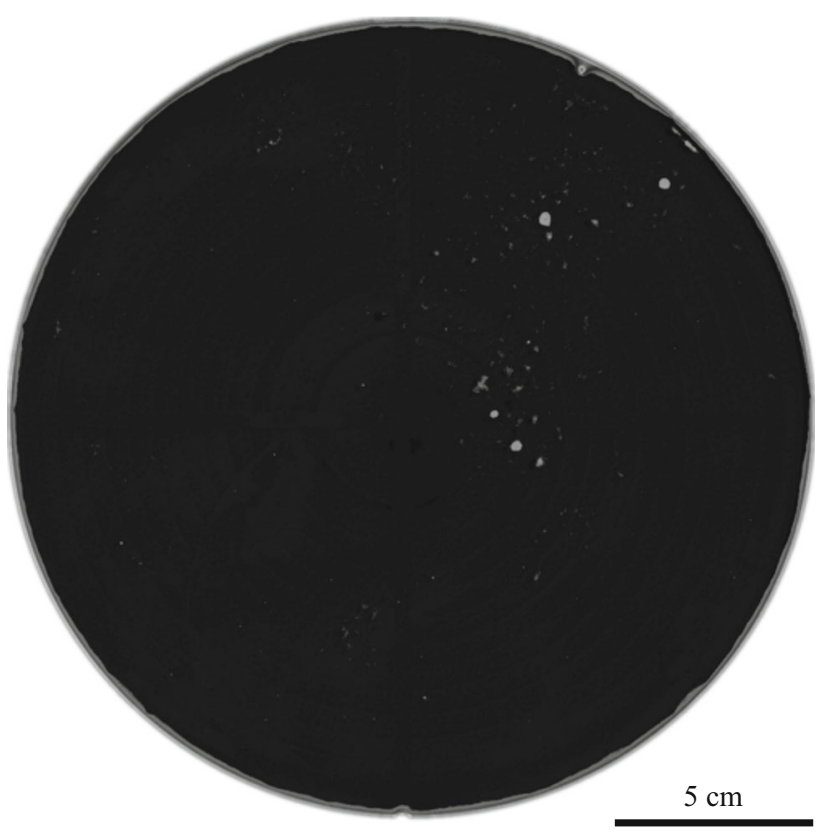

Fig. 3 Typical C-SAM result of $200 \mathrm{~mm}$ diameter ALPS wafers bonded in the ComBond ${ }^{\circledR}$ system at $150{ }^{\circ} \mathrm{C}$ 


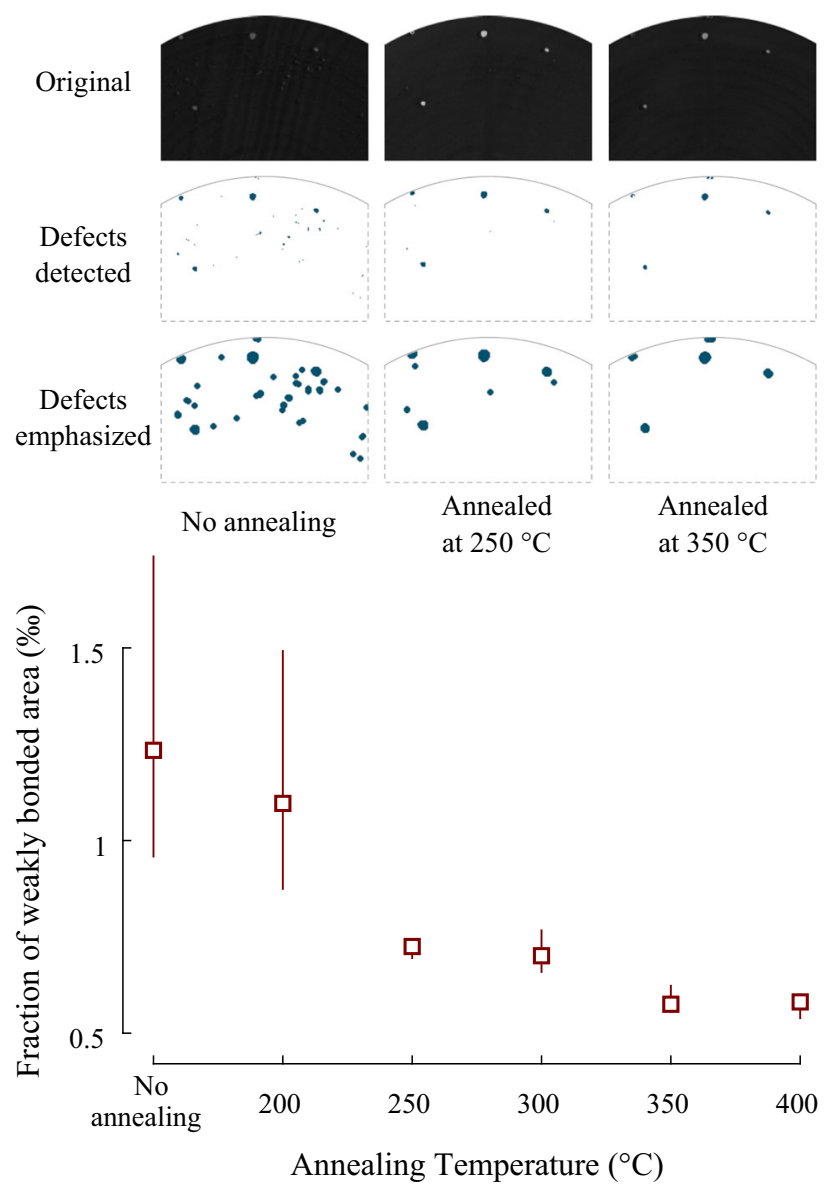

Fig. 4 Top: C-SAM results for a low-temperature wafer bond after thermal annealing at 250 and $350{ }^{\circ} \mathrm{C}$. Bottom: quantitative evaluation of the defect area

(especially of the small defects), Fig. 4 (top) also shows versions of the binarized images with the defects enlarged by dilation. This comparison shows that the defects smaller than a few millimeters vanish after the thermal treatment, more or less leaving only those defects that are caused by particles. A quantitative evaluation of the weakly bonded area shows a drop by a factor of two for annealing temperatures of $200{ }^{\circ} \mathrm{C}$ or more (see Fig. 4 bottom). We attribute this effect to the increased self-diffusion and the resulting closing of voids in $\mathrm{Al}$ at elevated temperatures (Volin and Balluffi 1968).

Compared to bonded ALPS wafer pairs, the samples produced from standard $\mathrm{Al}$ wafers showed significantly more weakly bonded or unbonded areas upon C-SAM inspection. For a qualitative comparison of the bond strength, a razor blade was inserted at the bonded interface (cf. Maszara et al. (1988)) and the approximate length of the resulting crack was measured with C-SAM. The crack length exhibited by the standard $\mathrm{Al}$ samples was $5 \%$ to $10 \%$ larger than that measured for ALPS ones. From the C-SAM measurements and the crack length measurements
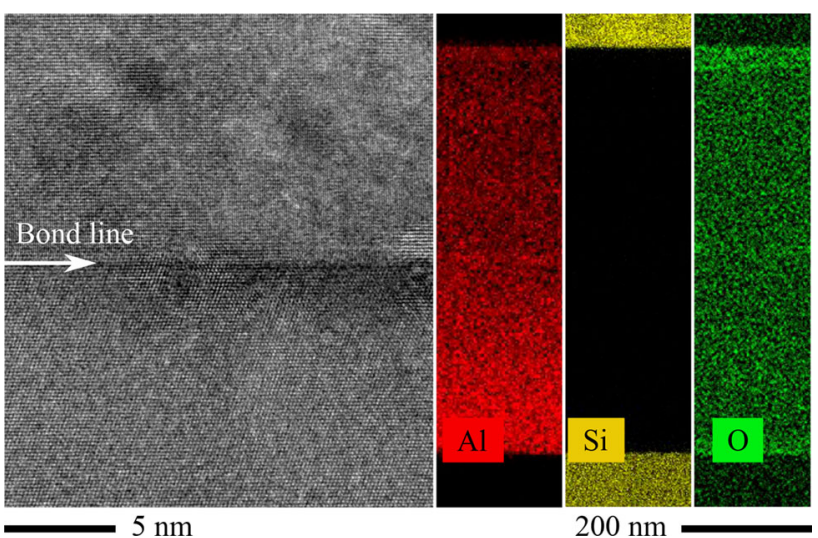

Fig. 5 High-resolution TEM image and EDX mapping of the interface of a ComBond ${ }^{\circledR}$ surface pretreated, low-temperature bonded wafer pair, showing atomic, oxide free contact

it can be concluded that the bonded ALPS wafers revealed higher bond strength than the standard Al wafers. The smaller grains observed in the ALPS wafers might be the reason for this difference. Smaller grains result in a higher density of grain boundaries, which in turn promotes diffusion of $\mathrm{Al}$ atoms, as the concentration of short-circuit diffusion paths is increased (Rebhan et al. 2014; Rebhan and Hingerl 2015).

The interfaces of the dry surface pretreated, low-temperature bonded ALPS wafer pairs were characterized by TEM and energy dispersive X-ray spectroscopy (EDX). As the high resolution TEM image in the left part of Fig. 5 shows, no amorphous layer separates the two Al metallization films. Similar observations were made byAkatsu et al. (1999) for single crystalline samples. The EDX mapping shown in the right part of Fig. 5 reveals that no oxide is accumulated near the interface. The oxide signal stems exclusively from the native oxide on the surface of the TEM specimen, which was exposed to air during TEM preparation.

\section{Conclusion}

Due to the native, chemically highly stable $\mathrm{Al}$ oxide layer, which obstructs diffusion of $\mathrm{Al}$ atoms between the two metallization layers, conventional $\mathrm{Al}-\mathrm{Al}$ wafer bonding requires extremely high processing temperatures and pressures. A dry surface pretreatment process, which removes the native oxide, is the key to enable $\mathrm{Al}-\mathrm{Al}$ wafer bonding at temperatures as low as $150{ }^{\circ} \mathrm{C}$, even with the lowest bonding pressure ever reported. Using the $\mathrm{EVG}^{\circledR} 580$ ComBond $^{\circledR}$ system with its surface pretreatment module, low-temperature bonding of unstructured $200 \mathrm{~mm}$ aluminum wafer pairs could be demonstrated for the first time. The bonding interface was inspected by C-SAM and 
TEM, and featured areas of oxide-free, atomic contact. Most of the voids that were not related to particles could be closed by an additional thermal annealing step $\left(350{ }^{\circ} \mathrm{C}\right.$ for $1 \mathrm{~h})$.

Acknowledgements Open access funding provided by Johannes Kepler University Linz. Financial support by the Austrian Federal Ministry of Science, Research and Economy and by the Austrian National Foundation for Research, Technology and Development is gratefully acknowledged.

Open Access This article is distributed under the terms of the Creative Commons Attribution 4.0 International License (http://crea tivecommons.org/licenses/by/4.0/), which permits unrestricted use, distribution, and reproduction in any medium, provided you give appropriate credit to the original author(s) and the source, provide a link to the Creative Commons license, and indicate if changes were made.

\section{References}

Akatsu T, Hosoda N, Suga T, Rühle M (1999) Atomic structure of Al/ Al interface formed by surface activated bonding. J Mater Sci $34: 4133$

Akatsu T, Sasaki G, Hosoda N, Suga T (1997) Microstructure and strength of Al-sapphire interface by means of the surface activated bonding method. J Mater Res 12:852

Cakmak E, Dragoi V, Pabo E, Matthias T, Alford TL (2009) Aluminum thermo compression bonding characterization. Mater Res Soc Symp Proc 1222:DD04

Evertsson J, Bertram F, Zhang F, Rullik L, Merte LR, Shipilin M, Soldemo M, Ahmadi S, Vinogradov N, Carlà F, Weissenrieder J,
Göthelid M, Pan J, Mikkelsen A, Nilsson JO, Lundgren E (2015) The thickness of native oxides on aluminum alloys and single crystals. Appl Surf Sci 349:826

Froemel J, Baum M, Wiemer M, Roscher F, Haubold M, Jia C, Gessner T (2011) Investigations of thermocompression bonding with thin metal layers. In: 16th international solid-state sensors, actuators and microsystems conference, pp 990-993

Hart RK (1956) The oxidation of aluminium in dry and humid oxygen atmospheres. Proc Roy Soc 236(1204):68

Kim TH, Howlader MMR, Itoh T, Suga T (2003) Room temperature $\mathrm{Cu}-\mathrm{Cu}$ direct bonding using surface activated bonding method. J Vac Sci Technol A 21:449

Lloyd JR (1999) Electromigration in integrated circuit conductors. J Phys D 32(17):109

Malik N, Schjølberg-Henriksen K, Poppe E, Taklo MMV, Finstad TG (2014) Al-Al thermocompression bonding for wafer-level MEMS sealing. Sens Actuat A 211:115

Malik N, Schjølberg-Henriksen K, Poppe E, Taklo MMV, Finstad TG (2015) Impact of $\mathrm{SiO} 2$ on $\mathrm{Al}-\mathrm{Al}$ thermocompression wafer bonding. J Micromech Microen 25:035025

Maszara WP, Goetz G, Caviglia A, McKitterick JB (1988) Bonding of silicon wafers for silicon-on-insulator. J Appl Phys 64:4943

Rebhan B, Hingerl K (2015) Physical mechanisms of copper-copper wafer bonding. J Appl Phys 118:135301

Rebhan B, Wimplinger M, Hingerl K (2014) Impact factors on low temperature $\mathrm{Cu}-\mathrm{Cu}$ wafer bonding. ECS Trans 64:369

Volin TE, Balluffi RW (1968) Annealing kinetics of voids and the self-diffusion coefficient in aluminum. Phys Stat Sol 25:163

Yun CH, Martin JR, Chen L, Frey TJ (2008a) Clean and conductive wafer bonding for MEMS. ECS Trans 16:117

Yun CH, Martin JR, Tarvin EB, Winbigler JT (2008b) Al to Al wafer bonding for MEMS encapsulation and 3-D interconnect. In: IEEE 21st international conference on micro electro mechanical systems, pp 810-813 